\title{
Improving the Power Electronics Laboratory teaching/learning process: an interactive web tool
}

\author{
F. D. Trujillo-Aguilera ${ }^{1}$, P. J. Sotorrío-Ruiz ${ }^{1}$ and E. B. Blázquez-Parra ${ }^{2}$ \\ ${ }^{1}$ Department of Electronic Technology \\ ${ }^{2}$ Department of Graphic Expression, Design and Projects \\ Industrial Engineering Technical School, University of Malaga, Malaga (Spain) \\ \{fdtrujillo, pjsotorrio, ebeatriz\}@uma.es
}

\begin{abstract}
The forthcoming European Higher Education Area implies an important change in the teaching/learning process: it is necessary to get students more involved as well as to promote their independence and active participation. To achieve this objective, the new teaching methodologies aimed at more effective and appropriate learning for professional practice involve the use of audiovisual, computer and multimedia tools on the part of lecturers. Therefore, a web tool, based on a content management system, has been developed for the teaching in Power Electronics Laboratory. Moreover, the use of these multimedia tools makes possible to promote the students independence. Finally, the use of this web tool results in a very significant increase in the motivation students.
\end{abstract}

Keywords-teaching/learning process; European Higher Education Area; Power Electronics Laboratory; educational methods

\section{INTRODUCTION}

The European Higher Education Area (EHEA) means an important challenge in the teaching/learning process. The aim is to achieve that student becomes the focus at which converge all efforts. In order to achieve this goal, it is necessary to involve more efficiently the students by means of boosting their independent study (self-learning) and, mainly, an active participation. This transition is happening at the same time as the increase in the development and use of new information technologies, simulations tools and educational platforms [1] [2].

The evolution of computers associated with the rapid emergence of internet and its associated tools has provided educators with a powerful and effective mechanism for information delivery. This environment can easily incorporate the latest hypermedia technologies (hypertexts, interactive simulations, videos/sounds, databases, remote-controlled instruments) to create and to manage educational courses, virtual laboratories, and virtual classrooms [3] [4]. The main advantages of educational systems based on internet environments are that they are independent of time and location, have a simple and familiar web browser-based interface, and offer the possibility of simultaneous attendance [3] [5]. With the advent of e-learning technologies, the accessibility of training, teaching, and learning has drastically increased. E-learning is worldwide emerging as the new paradigm of modern education [6].

It is demonstrated that the use of these systems can be a great help in solving this problem [7]. Thus, circuit simulation packages have become essential tools in many engineering courses such as power electronics. In fact, these simulation packages are strongly recommended for complementary and advanced circuit analysis now that they provide complex models with almost realistic behaviour.

The implemented web tool is based on CMS (Content Management System). A CMS is a collection of procedures used to manage work flow in a collaborative environment. These procedures control access to data, based on user roles; allow for a large number of people to contribute to and share stored data; improve the ease of report writing; improve communication between users; etc.

The web tool for Power Electronics Laboratory has been developed using open source software. The students can access the tool from any computer with internet connection. The interactive web is divided in two areas:

- User area, which is related to the web view as seen by the users. In the user area, students will be able to browse through the different contents as if they navigated in a website.

- Administration area, which can be only accessed by authorized users (teachers of the subject). In this area, the platform can be modified by the authorized users. All administrative aspects of the system are hidden in the user area. The administration area is, then, the backstage of the user area.

Indeed, the ease of handling of the administration area makes the platform was very easy to maintain, without web programming knowledge. The teacher is only concerned with the information they want to publish; and the CMS framework is responsible of all administrative and technical details.

Navigation through the web tool contents is achieved due to a basic menu, which consists of a home button and two dropdown buttons:

- Description of laboratory equipments: oscilloscope, power supply, wave generator, multimeter, clamps, and ALECOP modules.

- Definition of laboratory practices: eight practices, which include objectives, theoretical and practice analysis, simulation examples, implementation, tests, and sheet practice. 


\section{GENERAL FEATURES OF THE PLATFORM: CMS AND JOMMLA!}

A content management system (CMS) [8] is a collection of procedures used to manage work flow in a collaborative environment. These procedures can be manual or computerbased. The procedures are designed to do the following:

- Allow for a large number of people to contribute to and share stored data.

- Control access to data, based on user roles (defining which information users or user groups can view, edit, publish, etc.).

- Aid in easy storage and retrieval of data.

- Reduce repetitive duplicate input.

- Improve the ease of report writing.

- Improve communication between users.

In a CMS, data can be defined as nearly anything: documents, movies, pictures, phone numbers, scientific data, and so forth. CMS facilities are frequently used for storing, controlling, revising, semantically enriching, and publishing documentation. Serving as a central repository, the CMS increases the version level of new updates to an already existing file. Version control is one of the primary advantages of a CMS.

According to the directives of the EHEA [6], the virtual platform of Power Electronics Laboratory has the following objectives:

- Accessibility and interactivity: students accessing the platform from any computer with internet connection (at home, at their place of study, work, at the university, etc.).

- Flexibility: it allows the teacher a dynamic and adaptive content.

- Adaptability to the learning place.

- Cost savings: the distribution of the platform is free. Thus, the cost, space, flexibility and time are much lower than traditional distribution through books and notes.

To achieve these characteristics, the virtual platform of the Power Electronics Laboratory has been developed using a free software application called Joomla! [9], that is a Content Management System (CMS), based on PHP (Hypertex Pre Processor) and SQL (Structure Query Language), under General Public License (GPL). Access to it is free, and is available in this address: http://www.uma.es/investigadores/grupos/electronica_potencia/ laboratorio

The main features to use a CMS are:

- Distinguishes two zones: user area (the student), and administration area (the lecturer).
- The creators of the platform (lecturers) do not require technical knowledge of web programming, so they should only focus on the development of content. These contents are included in the platform through a text editor and are presented in the final hearing by the hierarchical nesting structures, which include articles, sections and categories.

\section{DESCRIPTION OF THE PLATFORM}

The virtual platform for Power Electronics Laboratory is an open access web tool, that have been created entirely with open source software, and whose purpose is to support the teaching of the subject of Power Electronics. The student can access the platform from any computer with internet connection.

The platform is divided into two areas:

- User Area, which corresponds with the view of the platform as seen by the user accessing it. From the user area, the student will be able to browse the different contents of the same as if you do it for a website.

- Administration Area, which can be accessed only by authorized users (lecturers of the subject) and from where they can edit the platform. All administrative aspects of the system are hidden from the common user. The administration area is, then, the backstage of the user area.

Indeed, the ease of handling and versatility of the administration area makes that the platform is very easy to maintain, without web programming knowledge. The teacher is only concerned with the information they publish, the CMS is responsible for all administrative and technical details.

\section{A. User Area}

When you access the platform through the link http://www.uma.es/investigadores/grupos/electronica_potencia/ laboratorio, the home page appears, from which the user can access all the contents of the subject (Fig. 1). With the design and structure employed, the student has fully accessible from the home page all the contents of the platform: description of equipment, description of practices, theoretical developments, simulations, animations, quizzes, useful links, etc.

The head, located on the top of the platform (Fig. 1), consists of the following elements (Fig. 2):

- Logo of the University of Malaga. Clicking on it, it is possible to return to the home page of the platform laboratory.

- Label, which indicates the name of the subject: Power Electronics Laboratory.

- Search, which consists of a box where the student can enter a word or phrase and the platform, provides as a result an ordered list of places where the word in question is founded in the platform and the route and the direct link to itself.

- Horizontal drop-down menu, which allows navigation by platform quickly and intuitively. It consists of three 
parts: home, description of equipment, and laboratory practice. In turn, each of these parts consists of a menu, as shown in Fig. 3, which will be described later.

In relation to the body (Fig. 1) is the element where all the contents of the platform is showed. It distinguishes:

- A static vertical menu located on the left side of the page, and gives a list of external links of interest to the student, and a button to contact the subject lecturers. This vertical menu only appears when you first access to the platform, in order to leave the maximum space to the contents of the practices and equipment description.

- Main body with a white background for easy reading and avoid eyestrain.

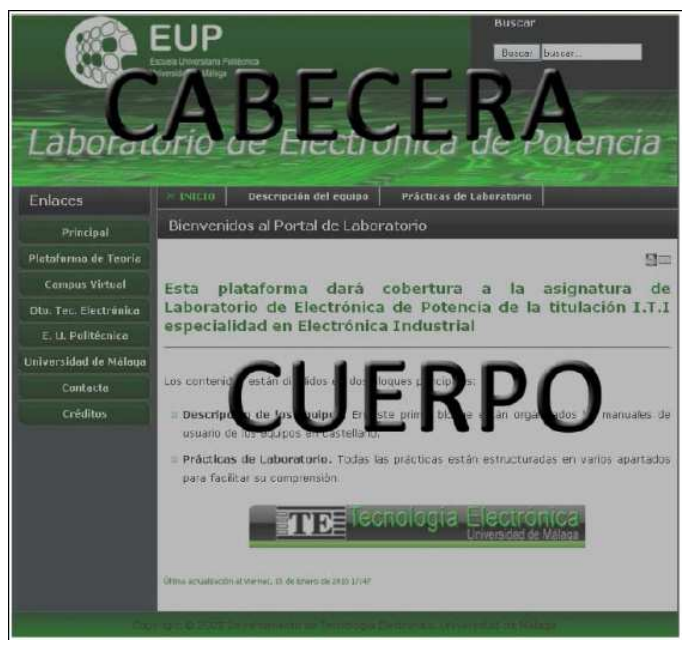

Figure 1. Head and body of the user area

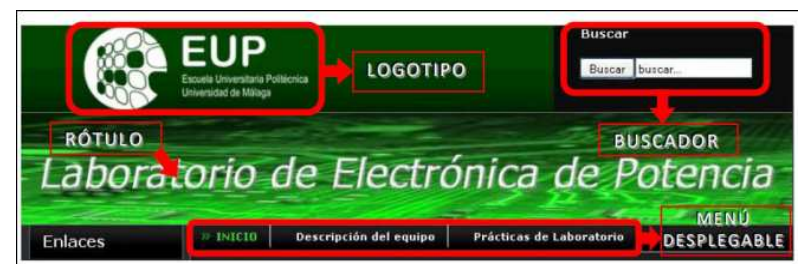

Figure 2. The platform head in detail

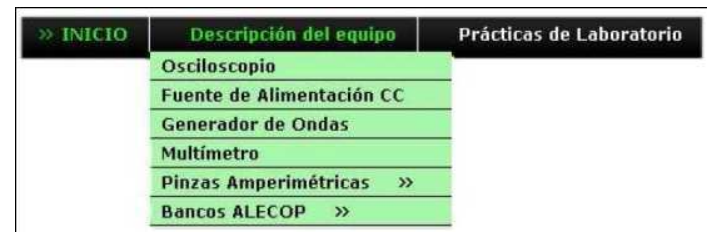

Figure 3. An example of a desplegable drop-down menu

\section{B. Browsing through the Platform}

Navigation through the contents of the platform is done by means of the horizontal menu shown in Fig. 3, which basically consists of a home button and two drop-down bottoms: description of equipment and laboratory practice.
In the module of equipment description are listed and showed all user manuals for the laboratory equipment that students should hand for the implementation of laboratory practices. The emphasis is on safety and proper functioning of the material. The manuals included are:

- Oscilloscope

- $\quad$ Power supply

- Wave generator

- Multimeter

- Clamps

- ALECOP [10] modules that set the bank of didactic training of Power Electronics

From the drop-down button "Laboratory Practice" is accessible to all laboratory practices besides a basic tutorial on PSpice simulation [11] of power switching converters.

Nowadays, the practices developed and available on the virtual interactive platform are:

- Practice 1: The thyristor. Using discrete electronic devices, students must determine the performance curve and design thyristor trigger circuits.

- Practice 2: Rectifier single phase semi-controlled. Using discrete electronic devices, students will implement a semi-controlled rectifier phase with several loads.

- Practice 3: Single phase rectifier fully-controlled bridge converter. Using discrete electronic devices, students will implement a single phase fully-controlled bridge converter with several loads.

- Practice 4: The triac, trigger circuits and AC (altern current) regulators. To study the operation of the triac, the performance curve and trigger circuits. To analyze the performance curve of the diac and develop a typical firing circuit with triac-diac. To implement, using triacs, an AC regulator.

- Practice 5: DC/DC (direct current) converter in fullbridge, PWM control. Using the power electronics training ALECOP, students must implement a DC/DC converter in full-bridge. The activation of the switches are made by means of the Pulse Width Modulation (PWM) voltage-switched bipolar and unipolar, analyzing the influence of various parameters on the voltage and current output.

- Practice 6: Single-phase full-bridge inverter, PWM control. Using the power electronics training ALECOP, students must implement a single phase PWM inverter full-bridge. A comparison form of bipolar and unipolar PWM control will be made.

- Practice 7: Single-phase full-bridge inverter. Quasisquare wave inverter. Using the power electronics training ALECOP, students will implement a singlephase quasi-square wave full-bridge inverter. 
- Practice 8: Three-phase square wave inverter. Using the power electronics training ALECOP, students must implement a three-phase square wave inverter. Star and triangle setting are used for the loads.

By clicking on each of these practices, a submenu is displayed with the following structure (Fig. 4):

- Objectives and material: a brief description of the practice objectives is presented, as well as the equipment necessary for its implementation.

- Theoretical analysis: each practice is enclosed with a clear and simple theory necessary for the appropriate understanding of the practice to develop.

- Practice implementation: this section provides all the useful elements for the assembly and development the practice. Several animations have been incorporated of each assembly, which step by step guide to the students in their implementation. Pressing the forward and backward arrows, it is displayed, step by step, the practices wired (Fig. 5).

- Simulation and examples: this section includes simulation examples of the different devices and converters to implement in the laboratory practice. To do this, students can download the file .CIR for PSpice simulation with different control elements.

- Self-assessment questionnaires: the use of online questionnaires for the assessment of students is a clear example of technological application in the field of education. The use of PHP technology used in this platform to create dynamic content is an important step in assessing the foreground. The responses from the questionnaires are sent automatically to email the lecturer, simplifying the evaluation process. Students have the possibility to send within their questionnaires online the graphic files collected from the oscilloscope, or any other file with extension .JPG, .JPEG, .PNP, .GIZ, .ZIP and .RAR.

- Sheet practice: this section would provide the former laboratory sheets in PDF format.

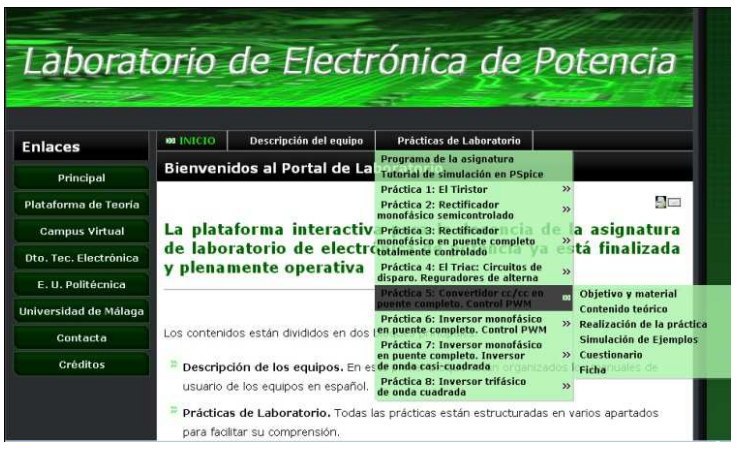

Figure 4. Drop-down menu of the laboratory practices

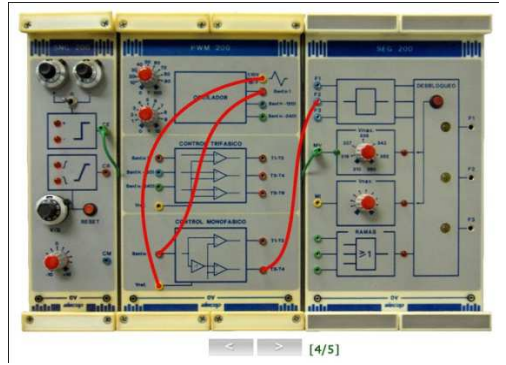

Figure 5. Example of animation of a practice implementation

\section{Administration Area}

To access to the administrative interface is achieved by the next

link:

http://www.uma.es/investigadores/grupos/electronica_potencia/ laboratorio/administrator

The administration area has restricted access for the subject lecturers, so it is necessary to enter a user name and password authorized (Fig. 6).

Platform administrators are the lecturers of the subject. They are therefore responsible to update, modify and structure the contents of the platform. When using CMS content, lecturers can perform these tasks without web programming knowledge.

In the administration area, the lecturer manages all the elements and applications for the development and maintenance of the contents of the user area.

The control panel of the administration homepage (Fig. 7) provides access to the functions and features of the platform by means of a series of direct links (Fig. 7: Manager) and navigation menu (Fig. 7: Menu). The control panel allows creating and managing all the information contained in the platform as traditional folders. Thus, the hierarchy used is as follows: sections containing categories and these containing items. This makes very easy to organize all the information in the administration area, regardless of how you configure the user area.

In addition to this, from the administration area the lecturer can access to other features such as languages, news, users, or enable access to the global configuration of the website.

The main tools for content creation in the web tool platform from the administration area are:

- Text Editor. It is used for preparing contents for the user zone. The editor interface is similar to other publishers, such as Microsoft Word, but with fewer options. The editor allows creating contents or articles where pictures can insert and any multimedia file (Java, Flash, videos, etc).

- Menu Manager. In order to create menus and associate it with a specific content. These created menus appear in the user area and they may show the desired content to be selected. 


\section{Acceso a la administración de Joomla!}

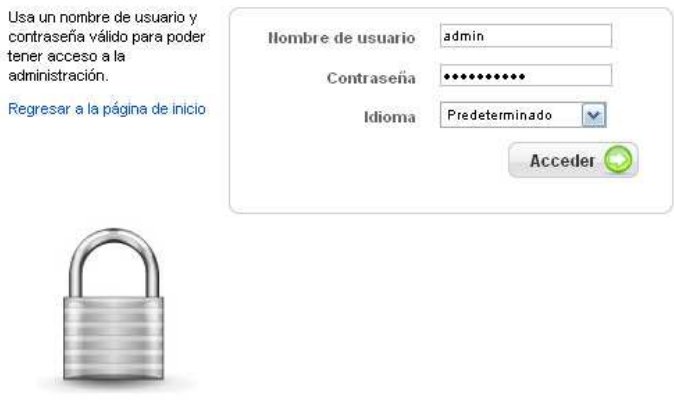

Figure 6. Administration area access

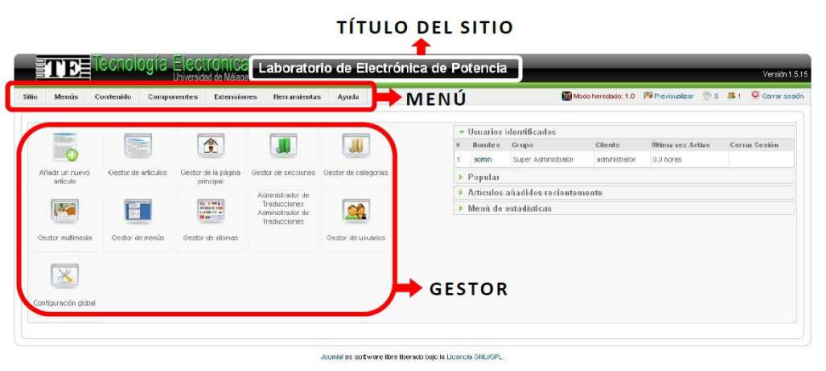

Figure 7. Administration homepage control panel

\section{DEVELOPMENT OF A LABORATORY CLASS}

The virtual web tool platform for Power Electronics Laboratory has been created as a complete interactive guide to the subject development of the Power Electronics Laboratory. In the presented platform, students find a description of all equipments and instruments used in the laboratory, the list of the practices carried out with discrete electronic devices and the power electronics training bank, practices simulation in PSpice and a set of online surveys that students must fill them at the end of each practice.

The laboratory course is taught in the Power Electronics Laboratory for three hours a week. The Power Electronics Laboratory has five workstations, with two o three students per workstation. Each workstation has the following equipment:

- Digital oscilloscope

- Function generator

- DC-AC power supply

- Digital multimeter

- Differential voltage probe

- Clamps

- Protoboard and discrete electronic devices

- Power electronics training bank

- Computer with internet connection to access the implemented platform and PSpice software simulation
As shown in the platform description, all practices have to be physically implemented either with discrete electronic devices or using the power electronics training bank. Software simulation such as PSpice is helpful, so it is used as additional material in the practices. But it is essential that students concurrently perform hardware-based laboratory experiments. It is a dangerous trend in many universities to move away from hardware to purely software-based laboratories, an approach that does not prepare to the students for the real world where they design, build, test or use real hardware. For these reason, simulations are used in our case as pre-laboratory investigations, which allow students to take an active involvement in the learning process by managing some aspects of the design before approaching the physical system.

\section{FROM THE STUDENT'S PERSPECTIVE: SURVEYS}

For this new implemented interactive tool, two surveys have been developed [12] [13] [14], for both students and lecturers, to validate this educational resource and their correct adaptation. One survey for students (satisfaction survey) and one for lecturers, defined in an expert group of five members (validation survey).

The results of these two questionnaires are taken into account for improving the interactive tool, only if the questionnaire results are not satisfied, measured in terms of a scale from 1 to 5 points. In this case, once the changes are introduced in the educational tool, the satisfaction and validation surveys are completed again, in order to check if the needed modifications have been performed adequately.

\section{A. Satisfaction survey}

The students validate several performance features of the tool. This questionnaire, for students, is composed of three fields, according to these aspects:

- Interface features: easy browsing, clear icons, disposition of menus, providing help, visible links, understandable menu, uniformity in all the screens, etc.

- Aesthetic features: well arranged information, clear texts, image quality, animation quality, colors, original design, correct letter size, motivating design, correct information volume in each screen, etc.

- Usefulness features: easy installation, versatile tool, instructions for use, it helps to understand the matter, etc.

\section{B. Validation survey}

Besides the three fields defined below, the validation questionnaires, for lecturers, consist of three fields more. These fields are:

- Technical features: multimedia elements, response time, audio support, file size, image motion, document printing, easy technical requirements, etc.

- Pedagogical features: lead learning, updated contents, self-evaluation, feedback, it evokes attention, 
redundant information, summaries, it is motivating, widening activities, etc.

- Skills and strategies: memorizing, comparison, analysis, creativity, interpretation, calculation, to solve problems, knowledge consolidation, etc.

\section{Results and analysis}

All the results derived from the surveys and presented in this section have been calculated by considering only the students who completed the questionnaires correctly. Table I shows the number of analyzed questionnaires in this study.

TABLE I. NUMBER OF ANALYZED QUESTIONNAIRES

\begin{tabular}{|c|c|}
\hline SURVEYS & NUMBER \\
\hline Satisfaction & 429 \\
\hline Validation & 40 \\
\hline
\end{tabular}

Tables II and III present the results of the satisfaction and validation questionnaires, in terms of mean values of all the answers related to the most important aspects of each questionnaires analysis, being necessary to take into account the value of the standard deviation. The responses of each questionnaire are marked from 1 (entirely disagree) to 5 (entirely agree).

TABLE II. SATISFACTION SURVEY ANALYSIS

\begin{tabular}{|c|c|c|}
\hline FEATURES & MEAN VALUE & STANDARD DEVIATION \\
\hline Interface & 4,56 & 0,24 \\
\hline Aesthetic & 4,21 & 0,17 \\
\hline Usefulness & 4,64 & 0.21 \\
\hline
\end{tabular}

TABLE III. VALIDATION SURVEY ANALYSIS

\begin{tabular}{|c|c|c|}
\hline FEATURES & MEAN VALUE & STANDARD DEVIATION \\
\hline Interface & 4,35 & 0,34 \\
\hline Aesthetic & 4,28 & 0,27 \\
\hline Usefulness & 4,56 & 0,45 \\
\hline Technical & 4,44 & 0,48 \\
\hline Pedagogical & 4,61 & 0,14 \\
\hline Skills/Strategies & 4,68 & 0,19 \\
\hline
\end{tabular}

Table II and III demonstrate that the features of the new interactive multimedia tool are considered, both students and lecturers, as very adequate and suitable for the study of Power Electronics and this tool achieves the proposed objectives in terms of pedagogical aspects and promotion of important skills and strategies.

\section{CONCLUSIONS AND FUTURE WORKS}

The interactive web tool, based on Jommla!, presented in this paper, is the suitable complementary material for the correct development of the Power Electronics Laboratory and for the consolidation of the theoretical concepts in the Power Electronics subject.

In one hand, the implementation of the platform, according to the EHEA paradigms, has achieved an important active participation of these subject students. In the other hand, the platform development, based on Jommla!, has allowed a very intuitive and easy handling tool. In this sense, the maintenance and updating of the tool can be performed by the lecturers.

This web tool is easily expandable with new versions and new contents, like new interactive tutorials related to the power electronics devices or new laboratory practices.

Finally, the authors insist that the interactive tool is a free internet resource worldwide.

Finally, related to the survey analysis, and with the idea in mind of complementing the questionnaire results, it can be very interesting to perform a detailed study of the obtained marks of the students and compared them with the previous students that could not use this new educational tool.

\section{REFERENCES}

[1] T. Martin and A. Serrano-Fernandez, "The role of new technologies in the learning process: Moodle as a teaching tool in Physics", Computer \& Education, vol. 52, pp. 35-44, Jan. 2009.

[2] G. Hwang, "A tutoring strategy supporting system for distance learning on computer networks", IEEE Trans. on Education, vol. 41, pp. 333343, Nov. 1998.

[3] H. A. Latchman, C. Salzmann, D. Gillet, and H. Bouzekri, "Information technology enhanced learning in distance and conventional education", IEEE Transactions on Education, vol. 42, no. 4, pp. 247-254, November 1999.

[4] A. A. Renshaw, J. H. Reinbel, C. A. Zukowski, K. Penn, R. O. McClintock, and M. B. Friedman, "An assessment of online engineering design problem presentation strategies", IEEE Transactions on Educations., vol. 43, no. 2, pp. 83-91, May 2000.

[5] M. J. Wirthlin and B. McMurtrey, "Web-based IP evaluation and distribution using applets", IEEE Transactions on Comput.-Aided Design Integrated Circuits and Systems, vol. 22, no. 8, pp. 985-994, Aug. 2003.

[6] The European Higher Education Area, Bologna Declaration, 1999.

[7] C. Elmas, Y. Sönmez, "An educational tool for power electronics circuits", Computer Applications in Engineering Education, vol. 18, pp. 157-165, March. 2010.

[8] D. Green, "At the leading edge: the atlas and CMS LHC experiments," World Scientific, Singapur, 2010.

[9] D. Rahmel, "Beginning Jommla!," 2nd edition, Springer-Verlag, New York, 2009.

[10] http://www.alecop.com/index.php?option=com_remository \&Itemid=46 \&lang=es [online]

[11] M. H. Rashid and H. M. Rashid, "PSpice for power electronics and electric power," Taylor and Franscis Group, 2006.

[12] E. Navarro, "Evaluación de materiales multimedia," Proyecto SAMIAL. Comunicación y Pedagogía, vol. 157, pp. 36-39, 1998.

[13] MVU, Michigan Virtual University, "Standard Quality on-line courses". Available, 2002: http://ideos.mivu.org/standards

[14] S. Alexander, and J. Hedberg, "Evaluating technology-based learning: Which model?", in K. Beattie, C. McNaught and S. Wills (Eds.), Interactive Multimedia in Education: Designing for Change in Teaching and Learning. Holland: Elsevier Science, 1994. 